\title{
PENERAPAN SPEECH RECOGNITION PADA PERANCANGAN APLIKASI PENCARIAN GEDUNG OLAHRAGA DENGAN METODE K-NEAREST NEIGHBOUR
}

\author{
M. Rifki Ramdani ${ }^{1}$, Wigar Kumara P. ${ }^{2}$, Hedry Aristianda ${ }^{3}$, Ferry Wahyu A. ${ }^{4}$, Joang Ipmawati $^{5}$ \\ Email: rifki.ramdani@students.amikom.ac.id, wigar.0730@students.amikom.ac.id, \\ hedry.aristianda@students.amikom.ac.id, ferry.ar@students.amikom.ac.id \\ Universitas AMIKOM Yogyakarta
}

\begin{abstract}
Abstrak
Berbagai macam manfaat dapat diperoleh dari berolahraga, selain dapat menyehatkan tubuh olahraga dapat meingkatkan tingkat konsentrasi. Jenis olahraga sangatlah bermacam-macam mulai dari olahraga ringan sampai berat. Olahraga dapat di lakukan di rumah maupun di Gedung olahraga. Namun untuk Gedung olahraga tidak selalu tersedia di daerah-daerah tertentu. Untuk mencari Gedung olahraga sedikit sulit jika memang tidak tahu daerah tempat tersebut. Untuk itu pada penelitian kali ini dikembangkan aplikasi untuk mencari gedung-gedung olahraga terdekat. Aplikasi ini menerapkan cabang dari teknologi kecerdasan buatan, yaitu speech recognition dengan metode k-nearest neighbour dalam pencarian Gedung olahraganya sendiri. Penggunaan speech recognition ini di maksudkan agar aplikasi ini dapat berjalan dengan lebih efisien.
\end{abstract}

Kata Kunci: pencarian gedung olahraga, speech recognition, k-nearest neighbour

\section{PENDAhUluaN}

Salah satu penyebab kurangnya berolahraga adalah kurangya tempat untuk berolahraga itu sendiri selain penyebab yang lainnya. Tempat untuk berolahraga sebenarnya dapat dimana saja menyesuaikan jenis olahraga itu sendiri. Tetapi ada beberapa jenis olahraga yang memang memerlukan tempat khusus untuk melaksanakan olahraga tersebut. Seperti olahraga bulu tangkis atau basket misalnya, olahraga ini memerlukan tempat yang biasa di sebut Gedung olahraga.

Namun di masa sekarang lahan-lahan kosong mulai di isi dengan perhotelan dan gedung-gedung lainnya sehingga sulit untuk menemukan gedung olahraga di sekitar tempat tinggal. Hal ini juga di persulit dengan tidak adanya tanda atau pentunjuk dimana tempat gedung olahraga berada, sehingga untuk beberapa masyarakat terutama anak kost yang memang belum mengenal daerah tempat kosnya berada memang menjadi kendala tersendiri dalam mencari gedung olahraga tersebut.

Dikarenakan permasahan tersebut peneliti membuat sebuah aplikasi android yang di maksudkan untuk menyelesaikan masalah tersebut. Aplikasi android ini menggabungkan cabang teknologi kecerdasan buatan natural language processing yaitu speech recognition dengan metode k-nearest neighbour. Natural language processing merupakan salah satu cabang kecerdasan buatan yang menitik beratkan pada pengolahan bahasa natural. Bahasa natural itu sendiri merupakan Bahasa yang biasa digunakan oleh manusia dalam berkomunikasi sehariharinya. Bahasa ini yang kemudian di terima oleh komputer membutuhkan pemrosesan dan pemahaman agar maksud dari pembicaraan manusia dapat ditangkap dan dipahami dengan baik oleh komputer.

Aplikasi pencarian gedung olahraga ini merupakan sebuah aplikasi yang berguna untuk menemukan gedung olahraga terdekat dari pengguna dan kemudian mencari rute perjalanan ke gedung olahraga yang dipilih. Dengan aplikasi ini pengguna dapat memulai pencarian dengan suara yang kemudian aplikasi memproses suara tersebut dan kemudian memulai pencarian gedung olahraga.

\section{Metode Penelitian}

\subsection{Natural Language Processing}

Natural language processing atau yang biasa di singkat NLP merupakan bagian dari kecerdasan buatan yang berfokus untuk membuat komputer paham terhadap bahasa sehari-hari manusia. NLP di gunakan untuk menganalisa atau menggambarkan teks atau suara yang di ucapkan oleh manusia dengan tujuan untuk memperoleh pemahaman bahasa manusia agar dapat di aplikasikan ke berbagai kegiatan manusia.

Pendekatan Natural Language Processing terbagi menjadi 4 kategori pendekatan yaitu simbolis, statistik, koneksi, dan hibrida.

Pada pendekatan simbolis ini pendekatan melakukan analisa yang mendalam terhadap fenomena linguistik melalui skema representasi 
pengetahuan yang sudah dipahami dengan baikdan algoritma yang terkait.

Pendekatan statistik ini menggunakan berbagai macam Teknik dalam matematika untuk mengembangkan model umum dari fenomena linguistik berdasarkan contoh yang nyata. Perbedaan dengan pendekatan simbolis adalah pendekatan ini menggunakan data yang dapat di observasi sebagai sumber utama bukti.

Pendekatan koneksis

Pendekatan ini hampir sama dengan pendekatan stastistik yang sama-sama menggunakan model umum dari fenomena linguistik. Yang membedakan dari pendekatan lainnya ialah pendekatan ini menggabungkan statistik learning dengan berbagai macam teori representasi. (Elizabeth D. Liddy, 2001).

\subsection{K-Nearest Neighbour}

K-Nearest Neighbour atau yang biasa di singkat K-NN adalah algoritma non-paramterik yang "malas". Dikatakan non prametrik karena K$\mathrm{NN}$ tidak membuat asumsi apapun pada distribusi datanya, dengan kata lain struktur model K-NN hanya di tentukan dari datanya saja. Sedangkan kata malas mengandung arti bahwa algoritma K$\mathrm{NN}$ ini tidak menggunakan titik data training untuk melakukan bentuk generalisasi apapun.

Metode ini melakukan kasifikasi dari objek yang jaraknya paling dekat dengan objek itu sendiri. Kemudian hasil dari query instance yang baru dikalsifikasikan menurut mayoritas dari kategorinya. Hasil dari klasifikasi adalah kelas yang paling banyak muncul.

\subsection{Cosine Similarity}

Cosine Similarity adalah suatu metode yang berfungsi untuk menghitung tingkat kesamaan atau kemiripan antara kalimat-kalimat yang ada.

Rumus dari Cosine Similarity adalah sebagai berikut:

$$
\frac{\sum_{n=1}^{j}(n A \times n B)}{\sqrt{\sum_{n=1}^{j}(n A)^{2}} \sqrt{\sum_{n=1}^{j}(n B)^{2}}}
$$

\section{Dengan:}

$n A=$ bobot kata ke- $n$ dari seluruh daftar kata pada kalimat $A$.

$n B=$ bobot kata ke- $n$ dari seluruh daftar kata pada kalimat

\subsection{Langkah Penelitian NLP}

1. Tokenisasi kata

Memecah dari satu kalimat menjadi katakata yang terpisah. Kata yang sudah terpisah ini biasa di sebut Token. Tokenisasi hanya memisahkan setiap ada spasi dan tanda baca di antara kata.

2. Mempredikisi bagian bagian kelas kata dari setiap token

Mengetahui atau memprediksi kelas kata dari setiap token yang ada.

3. Mengidentifikasi Stopwords

Mengidentifikasi kata umum yang dianggap tidak memiliki makna, dan kemudian membuangnya.

\subsection{Langkah Penelitian K-NN}

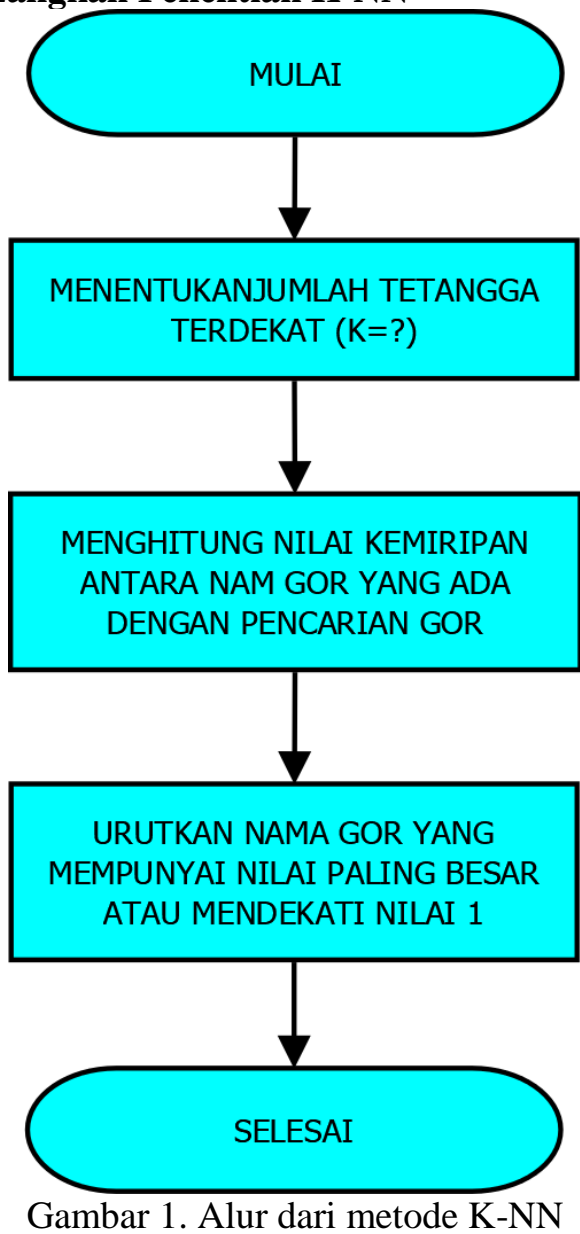

Pada Gambar 1 di atas ini merupakan alur algoritma dari metode K-Nearest Neighbour. Alur ini di mulai dari menentukan jumlah tetangga terdekat. Setelah menentukan nilai terdekat kemudian alur selanjutnya adalah menghitung nilai kemiripan antara nama gedung olahraga yang ada dengan pencarian gedung olahraga yang sudah di inputkan dengan menggunakan rumus Cosine Similarity. Alur selanjutnya adalah mengurutkan nama gedung olahraga yang mempunyai nilai paling besar atau yang mendekati nilai 1 (satu). 


\section{Hasil dan Pembahasan}

Dari hasil penelitian yang sudah dilakukan

1. Data Nama Gedung Olahraga

Data nama gedung olahraga disini dibagi menjadi 2 bagian penting. Yang pertama adalah data 3 Document Nama Gedung Olahraga yang terdapat di Yogyakarta dan yang kedua adalah 1 data sampel query.

2. Preprocessing

Dari data kedua bagian penting tadi dilakukan tokenisasi dengan memecah dari satu kalimat menjadi kata-kata yang terpisah yang disebut Token. Dari Token dihilangkan kata yang telah muncul sebelumnya menjadi TERM. Setelah tahap tokenisasi dilakukan proses stopwors removal yaitu menghilangkan kata-kata yang tidak memiliki makna atau yang memang tidak di perlukan. Dalam peneletian ini data yang digunakan tidak perlu dilakukan proses stemming karena data-data yang di gunakan merupakan nama suatu objek sehingga tidak memiliki imbuhan.

\begin{tabular}{|c|c|c|c|}
\hline \multicolumn{5}{|c|}{ TERM } \\
\hline Gedung & Gajah mada & Badminton & Pandugo \\
\hline Olahraga & Seturan & Janti & Corongan \\
\hline UNY & Bulutangkis & Gang damar & Margajaya \\
\hline Jalan & FIK & SMPN1 & Serba guna \\
\hline Colombo & Negeri & Cikditiro & Pringwulung \\
\hline Karang malang & Yogyakarta & Kamandanue & Jatayu \\
\hline Lembah & Kuningan & Benjeng & Condong catur \\
\hline UGM & Klebengan & Maguwoharjo & Kadisoka \\
\hline Sport & Gor pemuda & BLTP & \multirow{2}{|}{} \\
\cline { 1 - 2 } Center & Agro & Bener & \multicolumn{1}{|c}{} \\
\cline { 1 - 2 } Universitas & Catur tunggal & Tegalrejo &
\end{tabular}

Tabel 1. Hasil tokenisasi dan stopwords removal

Tabel 1 diatas menunjukan hasil tokenisasi dan stopwords removal dari 2 data yang sudah ada.

3. Menentukan bobot (width) dari setiap term di kedua bagian yaitu 3 Document Nama Gedung Olahraga yang terdapat di Yogyakarta dan 1 data sampel query dengan cara menghitung TF IDF. Menentukan jumlah kemunculan kata pada setiap dokumen:

\begin{tabular}{|c|c|c|c|c|c|}
\hline \multirow{2}{*}{ Index } & \multirow{2}{*}{ Daftar Kata } & \multicolumn{5}{|c|}{ Jumlah Kemunculan Kata (tf) } \\
\cline { 3 - 6 } & & D1 & D2 & D3 & Query \\
\hline 1 & Gedung & 4 & 4 & 4 & 1 \\
\hline 2 & Olahraga & 4 & 4 & 3 & 1 \\
\hline 3 & UNY & 2 & 0 & 0 & 0 \\
\hline 4 & Jalan & 3 & 3 & 2 & 1 \\
\hline 5 & Colombo & 1 & 0 & 0 & 0 \\
\hline 6 & Karang malang & 1 & 0 & 0 & 0 \\
\hline 7 & Lembah & 1 & 0 & 0 & 0 \\
\hline
\end{tabular}

\begin{tabular}{|c|c|c|c|c|c|}
\hline 8 & UGM & 1 & 0 & 0 & 0 \\
\hline 9 & Sport & 1 & 1 & 0 & 0 \\
\hline 10 & Center & 1 & 1 & 0 & 0 \\
\hline 11 & Universitas & 3 & 0 & 0 & 0 \\
\hline 12 & Gajah mada & 1 & 0 & 0 & 0 \\
\hline 13 & Seturan & 1 & 0 & 0 & 0 \\
\hline 14 & Bulutangkis & 1 & 0 & 0 & 0 \\
\hline 15 & FIK & 1 & 0 & 0 & 0 \\
\hline 16 & Negeri & 2 & 0 & 0 & 0 \\
\hline 17 & Yogyakarta & 2 & 1 & 1 & 0 \\
\hline 18 & Kuningan & 1 & 0 & 0 & 0 \\
\hline 19 & Klebengan & 0 & 2 & 0 & 0 \\
\hline 20 & Gor pemuda & 0 & 1 & 0 & 0 \\
\hline 21 & Agro & 0 & 1 & 0 & 0 \\
\hline 22 & Catur tunggal & 0 & 1 & 0 & 0 \\
\hline 23 & Badminton & 1 & 1 & 1 & 0 \\
\hline 24 & Janti & 0 & 1 & 0 & 0 \\
\hline 25 & Gang damar & 0 & 1 & 0 & 0 \\
\hline 26 & SMPN1 & 0 & 1 & 0 & 0 \\
\hline 27 & Cikditiro & 0 & 1 & 0 & 0 \\
\hline 28 & Kamandanue & 0 & 1 & 0 & 0 \\
\hline 29 & Benjeng & 0 & 1 & 0 & 0 \\
\hline 30 & Maguwoharjo & 0 & 1 & 2 & 1 \\
\hline 31 & BLTP & 0 & 0 & 1 & 0 \\
\hline 32 & Bener & 0 & 0 & 1 & 0 \\
\hline 33 & Tegalrejo & 0 & 0 & 1 & 0 \\
\hline 34 & Pandugo & 0 & 0 & 1 & 0 \\
\hline 35 & Corongan & 0 & 0 & 1 & 0 \\
\hline 36 & Margajaya & 0 & 0 & 1 & 1 \\
\hline 37 & Serba guna & 0 & 0 & 1 & 0 \\
\hline 38 & Pringwulung & 0 & 0 & 2 & 0 \\
\hline 39 & Jatayu & 0 & 0 & 1 & 0 \\
\hline 40 & Condong catur & 0 & 0 & 1 & 0 \\
\hline 41 & Kadisoka & 0 & 1 & 1 & 1 \\
\hline
\end{tabular}

Tabel 2. Hasil kemunculan kata (TF)

Setelah di tentukan jumlah kemunculan katanya kemudian menentukan Inverse Document Frequency (IDF) dengan rumus:

$$
I D F_{i}=\log \left(N / d f_{i}\right)
$$

Dengan:

$$
\begin{array}{ll}
I D F_{i} & =\text { Inverse Document Frequency } \\
\mathrm{N} & =\text { Jumlah seluruh data } \\
d f_{i} & =\text { Jumlah dokumen yang mengandung }
\end{array}
$$
term

Menentukan bobot (wdt) dengan mengalikan jumlah kemunculan kata (TF) setiap dokumen dengan Inverse Document Frequency dengan rumus:

$$
W=T F x I D F_{i}
$$

Dengan :

$W \quad=$ bobot

$T F \quad=$ jumlah kemunculan kata

$I D F_{i} \quad=$ Inverse Document Frequency

\begin{tabular}{|c|c|c|c|c|}
\hline \multirow{2}{*}{ idf } & \multicolumn{4}{|c|}{$\mathrm{W}=\mathrm{tf} *$ idf } \\
\cline { 2 - 5 } & $\mathrm{D} 1$ & $\mathrm{D} 2$ & $\mathrm{D} 3$ & Query \\
\hline 0 & 0 & 0 & 0 & 0 \\
\hline 0 & 0 & 0 & 0 & 0 \\
\hline 0.602059991 & 1.20412 & 0 & 0 & 0 \\
\hline
\end{tabular}




\begin{tabular}{|c|c|c|c|c|}
\hline 0 & 0 & 0 & 0 & 0 \\
\hline 0.602059991 & 0.60206 & 0 & 0 & 0 \\
\hline 0.602059991 & 0.60206 & 0 & 0 & 0 \\
\hline 0.602059991 & 0.60206 & 0 & 0 & 0 \\
\hline 0.602059991 & 0.60206 & 0 & 0 & 0 \\
\hline 0.301029996 & 0.30103 & 0.30103 & 0 & 0 \\
\hline 0.301029996 & 0.30103 & 0.30103 & 0 & 0 \\
\hline 0.602059991 & 1.80618 & 0 & 0 & 0 \\
\hline 0.602059991 & 0.60206 & 0 & 0 & 0 \\
\hline 0.602059991 & 0.60206 & 0 & 0 & 0 \\
\hline 0.602059991 & 0.60206 & 0 & 0 & 0 \\
\hline 0.602059991 & 0.60206 & 0 & 0 & 0 \\
\hline 0.602059991 & 1.20412 & 0 & 0 & 0 \\
\hline 0.124938737 & 0.249877 & 0.124939 & 0.124939 & 0 \\
\hline 0.602059991 & 0.60206 & 0 & 0 & 0 \\
\hline 0.602059991 & 0 & 1.20412 & 0 & 0 \\
\hline 0.602059991 & 0 & 0.60206 & 0 & 0 \\
\hline 0.602059991 & 0 & 0.60206 & 0 & 0 \\
\hline 0.602059991 & 0 & 0.60206 & 0 & 0 \\
\hline 0.124938737 & 0.124939 & 0.124939 & 0.124939 & 0 \\
\hline 0.602059991 & 0 & 0.60206 & 0 & 0 \\
\hline 0.602059991 & 0 & 0.60206 & 0 & 0 \\
\hline 0.602059991 & 0 & 0.60206 & 0 & 0 \\
\hline 0.602059991 & 0 & 0.60206 & 0 & 0 \\
\hline 0.602059991 & 0 & 0.60206 & 0 & 0 \\
\hline 0.602059991 & 0 & 0.60206 & 0 & 0 \\
\hline 0.124938737 & 0 & 0.124939 & 0.249877 & 0.124939 \\
\hline 0.602059991 & 0 & 0 & 0.60206 & 0 \\
\hline 0.602059991 & 0 & 0 & 0.60206 & 0 \\
\hline 0.602059991 & 0 & 0 & 0.60206 & 0 \\
\hline 0.602059991 & 0 & 0 & 0.60206 & 0 \\
\hline 0.602059991 & 0 & 0 & 0.60206 & 0 \\
\hline 0.301029996 & 0 & 0 & 0.30103 & 0.30103 \\
\hline 0.602059991 & 0 & 0 & 0.60206 & 0 \\
\hline 0.602059991 & 0 & 0 & 1.20412 & 0 \\
\hline 0.602059991 & 0 & 0 & 0.60206 & 0 \\
\hline 0.602059991 & 0 & 0 & 0.60206 & 0 \\
\hline 0.124938737 & 0 & 0.124939 & 0.124939 & 0.124939 \\
\hline
\end{tabular}

Tabel 3. Hasil pembobotan setiap dokumen dengan mengalikan TF dengan IDF

4. Menghitung kemiripan setiap dokumen yang ada dengan query dengan rumus Cosine Similarity :

Dengan:

$$
\frac{\sum_{n=1}^{j}(n A \times n B)}{\sqrt{\sum_{n=1}^{j}(n A)^{2}} \sqrt{\sum_{n=1}^{j}(n B)^{2}}}
$$

$n A=$ bobot kata ke- $n$ dari seluruh daftar kata pada kalimat $A$.

$n B=$ bobot kata ke- $n$ dari seluruh daftar kata pada kalimat $B$.
Mengalikan skalar antara query dengan tiap dokumen yang ada. Hasil perkalian dari setiap dokumen kemudian di jumlahkan.

\begin{tabular}{|c|c|c|c|c|}
\hline \multirow{2}{*}{ Index } & \multirow{2}{*}{ Daftar Kata } & \multicolumn{3}{|c|}{$W_{q} \times D_{i}$} \\
\hline & & D1 & D2 & D3 \\
\hline 1 & Gedung & 0 & 0 & 0 \\
\hline 2 & Olahraga & 0 & 0 & 0 \\
\hline 3 & UNY & 0 & 0 & 0 \\
\hline 4 & Jalan & 0 & 0 & 0 \\
\hline 5 & Colombo & 0 & 0 & 0 \\
\hline 6 & Karang malang & 0 & 0 & 0 \\
\hline 7 & Lembah & 0 & 0 & 0 \\
\hline 8 & UGM & 0 & 0 & 0 \\
\hline 9 & Sport & 0 & 0 & 0 \\
\hline 10 & Center & 0 & 0 & 0 \\
\hline 11 & Universitas & 0 & 0 & 0 \\
\hline 12 & Gajah mada & 0 & 0 & 0 \\
\hline 13 & Seturan & 0 & 0 & 0 \\
\hline 14 & Bulutangkis & 0 & 0 & 0 \\
\hline 15 & FIK & 0 & 0 & 0 \\
\hline 16 & Negeri & 0 & 0 & 0 \\
\hline 17 & Yogyakarta & 0 & 0 & 0 \\
\hline 18 & Kuningan & 0 & 0 & 0 \\
\hline 19 & Klebengan & 0 & 0 & 0 \\
\hline 20 & Gor pemuda & 0 & 0 & 0 \\
\hline 21 & Agro & 0 & 0 & 0 \\
\hline 22 & Catur tunggal & 0 & 0 & 0 \\
\hline 23 & Badminton & 0 & 0 & 0 \\
\hline 24 & Janti & 0 & 0 & 0 \\
\hline 25 & Gang damar & 0 & 0 & 0 \\
\hline 26 & SMPN1 & 0 & 0 & 0 \\
\hline 27 & Cikditiro & 0 & 0 & 0 \\
\hline 28 & Kamandanue & 0 & 0 & 0 \\
\hline 29 & Benjeng & 0 & 0 & 0 \\
\hline 30 & Maguwoharjo & 0 & 0.01561 & 0.031219 \\
\hline 31 & BLTP & 0 & 0 & 0 \\
\hline 32 & Bener & 0 & 0 & 0 \\
\hline 33 & Tegalrejo & 0 & 0 & 0 \\
\hline 34 & Pandugo & 0 & 0 & 0 \\
\hline 35 & Corongan & 0 & 0 & 0 \\
\hline 36 & Margajaya & 0 & 0 & 0.090619 \\
\hline 37 & Serba guna & 0 & 0 & 0 \\
\hline 38 & Pringwulung & 0 & 0 & 0 \\
\hline 39 & Jatayu & 0 & 0 & 0 \\
\hline 40 & Condong catur & 0 & 0 & 0 \\
\hline 41 & Kadisoka & 0 & 0.01561 & 0.01561 \\
\hline & Total & 0 & 0.031219 & 0.137448 \\
\hline
\end{tabular}

Tabel 4. Hasil perkalian skalar antara query dengan tiap dokumen

Menghitung panjang vektor setiap dokumen dan query dengan cara mengkuadratkan setiap 
bobotnya. Hasil pengkuadratan di jumlahkan kemudian di akar.

\begin{tabular}{|c|c|c|c|c|}
\hline \multirow{2}{*}{ Daftar Kata } & \multicolumn{4}{|c|}{ Panjang Vektor } \\
\hline & D1 & D2 & D3 & Query \\
\hline Gedung & 0 & 0 & 0 & 0 \\
\hline Olahraga & 0 & 0 & 0 & 0 \\
\hline UNY & 1.449905 & 0 & 0 & 0 \\
\hline Jalan & 0 & 0 & 0 & 0 \\
\hline Colombo & 0.362476 & 0 & 0 & 0 \\
\hline $\begin{array}{l}\text { Karang } \\
\text { malang }\end{array}$ & 0.362476 & 0 & 0 & 0 \\
\hline Lembah & 0.362476 & 0 & 0 & 0 \\
\hline UGM & 0.362476 & 0 & 0 & 0 \\
\hline Sport & 0.090619 & 0.090619 & 0 & 0 \\
\hline Center & 0.090619 & 0.090619 & 0 & 0 \\
\hline Universitas & 3.262286 & 0 & 0 & 0 \\
\hline Gajah mada & 0.362476 & 0 & 0 & 0 \\
\hline Seturan & 0.362476 & 0 & 0 & 0 \\
\hline Bulutangkis & 0.362476 & 0 & 0 & 0 \\
\hline FIK & 0.362476 & 0 & 0 & 0 \\
\hline Negeri & 1.449905 & 0 & 0 & 0 \\
\hline Yogyakarta & 0.062439 & 0.01561 & 0.01561 & 0 \\
\hline Kuningan & 0.362476 & 0 & 0 & 0 \\
\hline Klebengan & 0 & 1.449905 & 0 & 0 \\
\hline Gor pemuda & 0 & 0.362476 & 0 & 0 \\
\hline Agro & 0 & 0.362476 & 0 & 0 \\
\hline Catur tunggal & 0 & 0.362476 & 0 & 0 \\
\hline Badminton & 0.01561 & 0.01561 & 0.01561 & 0 \\
\hline Janti & 0 & 0.362476 & 0 & 0 \\
\hline Gang damar & 0 & 0.362476 & 0 & 0 \\
\hline SMPN1 & 0 & 0.362476 & 0 & 0 \\
\hline Cikditiro & 0 & 0.362476 & 0 & 0 \\
\hline Kamandanue & 0 & 0.362476 & 0 & 0 \\
\hline Benjeng & 0 & 0.362476 & 0 & 0 \\
\hline Maguwoharjo & 0 & 0.01561 & 0.062439 & 0.01561 \\
\hline BLTP & 0 & 0 & 0.362476 & 0 \\
\hline Bener & 0 & 0 & 0.362476 & 0 \\
\hline Tegalrejo & 0 & 0 & 0.362476 & 0 \\
\hline Pandugo & 0 & 0 & 0.362476 & 0 \\
\hline Corongan & 0 & 0 & 0.362476 & 0 \\
\hline Margajaya & 0 & 0 & 0.090619 & 0.090619 \\
\hline Serba guna & 0 & 0 & 0.362476 & 0 \\
\hline Pringwulung & 0 & 0 & 1.449905 & 0 \\
\hline Jatayu & 0 & 0 & 0.362476 & 0 \\
\hline $\begin{array}{c}\text { Condong } \\
\text { catur }\end{array}$ & 0 & 0 & 0.362476 & 0 \\
\hline Kadisoka & 0 & 0.01561 & 0.01561 & 0.01561 \\
\hline Total & 9.683669 & 4.955868 & 4.549602 & 0.121838 \\
\hline Akar & 3.111859 & 2.226178 & 2.13298 & 0.349054 \\
\hline$\sqrt{ } \mathrm{Di} * \sqrt{\text { Query }}$ & 1.086206 & 0.777055 & 0.744524 & \\
\hline Hasil Akhir & 0 & 0.040177 & 0.184612 & \\
\hline
\end{tabular}

Tabel 5. Hasil pengkuadratan setiap bobot

Pada tabel 5 diatas setiap akar dokumen dengan akar query dikalikan masing. Kemudian total pada tabel 5 setiap dokumennya di bagi dengan hasil perkalian $(\sqrt{ } \mathrm{Di} * \sqrt{ }$ Query) pada setiap dokumen yang sama.

5. Mengurutkan hasil akhir dengan nilai yang paling tinggi ke paling rendah

\begin{tabular}{|c|c|c|}
\hline Cos(Query, Di) & Nilai & Urutan \\
\hline Cos(Query, D1) & 0 & 3 \\
\hline Cos(Query, D2) & 0.040177 & 2 \\
\hline Cos(Query, D3) & 0.184612 & 1 \\
\hline
\end{tabular}

Tabel 6. Hasil pengurutan nilai

6. Tampilan prototype dari aplikasi pencari Gedung Olahraga

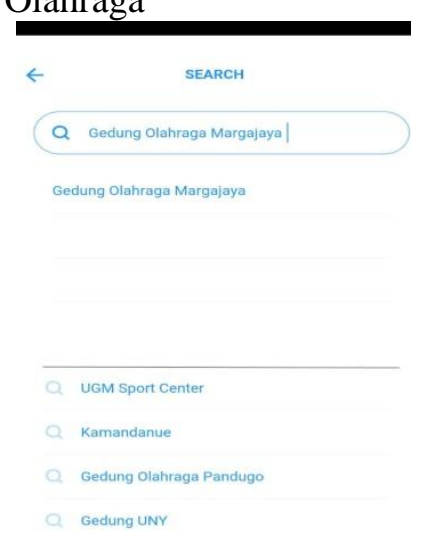

\section{Gambar 2. Desain Prototype Input Pencarian GOR.}

Pada Gambar 2, ketika menginputkan pencarian nama Gedung Olahraga Margajaya maka pada aplikasi akan muncul daftar nama gedung olahraga yang memiliki kemiripan dengan Gedung Olahraga Margajaya.

\section{Kesimpulan}

Dengan menerapkan Natural Language Processing dan K-Nearest Neighbour pada aplikasi ini dapat meningkatkan efektifitas pencarian dalam mencari gedung olahraga terdekat. Aplikasi ini juga dapat menampilkan list nama gedung olahraga yang memiliki kemiripan dengan yang di inputkan di pencarian.

Dalam aplikasi ini Natural Language Processing dapat membuat user lebih efektif dalam menggunakan aplikasi ini, hal ini dikarenakan user tidak perlu mengetikkan nama gedung yang ingin di cari 


\section{Daftar Pustaka}

[1] Algorithm, N. (2018). Penerapan Teknik Klasifikasi Untuk Prediksi Kelulusan Mahasiswa Menggunakan Algoritma KNearest Neighbour, 17(4), 395-403.

[2] Elektro, J. T., Studi, P., Elektro, T., Teknik, F., Buana, U. M., \& Uno, A. (n.d.). PERANCANGAN APLIKASI VOICE COMMAND RECOGNITION BERBASIS ANDROID DAN ARDUINO UNO Akhmad Wahyu Dani, Andi Adriansyah, Dodi Hermawan, 7(1), 11-19.

[3] Gunadarma, U. (2008). NATURAL LANGUAGES PROCESSING (NLP) KOMUNIKASI BAHASA NATURAL DENGAN ACTOR, (Kommit), 20-21.

[4] Kallmeyer, L. (2016). Machine Learning for natural language processing, 1-28.

[5] Neighbor, M. M. K. (2018). Klasifikasi mutu telur berdasarkan fitur warna dengan menggunakan metode k-nearest neighbor, 1188-1193.

[6] Suciadi, J. (2014). Studi Analisis MetodeMetode Parsing Dan Interpretasi Semantik Pada Natural Language Processing. Jurnal Informatika, Fakultas Teknologi Industri, Universitas Kristen Petra, 2(1), 13-22. https://doi.org/10.9744/informatika.2.1.pp.

$13-22$ 